\title{
Espaçamentos entre plantas e adição de cama-de-frango na produção de biomassa das plantas e na composição química dos frutos da Campomanesia adamantium
}

\author{
(Cambess.) O. Berg.
}

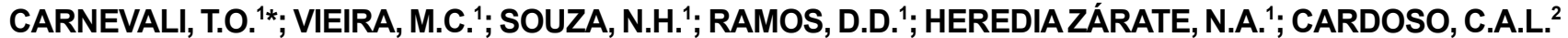 \\ ${ }^{1}$ UFGD-FCA, Caixa Postal 533, CEP: 79804-970, Dourados-Brasil ${ }^{2}$ UEMS-Cidade Universitária, Caixa Postal 351, \\ CEP: 79804-970, Dourados-Brasil *thiagocarnevali@live.com
}

\begin{abstract}
RESUMO: O objetivo deste trabalho foi avaliar o efeito de espaçamentos entre plantas e o uso ou não de cama-de-frango semidecomposta incorporada ao solo na produção de biomassa das plantas e nos teores de fenóis, flavonóides e atividade antioxidante do extrato dos frutos da Campomanesia adamantium. O experimento foi desenvolvido no Horto de Plantas Medicinais HPM, da Universidade Federal da Grande Dourados/UFGD, em Dourados-MS. Foi estudada a C. adamantium com cinco espaçamentos entre plantas, na linha $(0,30 ; 0,35 ; 0,40 ; 0,45$ e $0,50 \mathrm{~m}) \mathrm{e}$ sem, ou com, cama-de-frango semidecomposta incorporada ao solo na dose de $10 \mathrm{t} \mathrm{ha}^{-1}$. Os tratamentos foram arranjados como fatorial $5 \times 2$, no delineamento experimental de blocos casualizados, com quatro repetições. Aos 390 dias após o transplante as plantas possuíam $54,89 \mathrm{~cm}$ de altura, $10,01 \mathrm{~mm}$ de diâmetro de caule e 178,27 folhas por planta. Os diâmetros, longitudinal $(17,34 \mathrm{~mm})$ e transversal $(18,07 \mathrm{~mm})$, dos frutos não variaram com os espaçamentos e nem com o uso da cama-de-frango. O maior número de frutos $(28,56$ frutos planta-1) e a maior massa fresca dos frutos $\left(83,65 \mathrm{~g} \mathrm{planta}^{-1}\right)$ foram das plantas cultivadas sob os espaçamentos de $0,32 \mathrm{~m}$ e $0,35 \mathrm{~m}$ entre plantas, respectivamente, independente do uso ou não da cama-de-frango. A cama-de-frango induziu aumento significativo no teor de fenóis e reduziu o teor de flavonóides e a atividade antioxidante da polpa dos frutos. A cama-de-frango não influenciou a produtividade da C. adamantium nem a composição química dos frutos. Recomenda-se o uso do espaçamento $0,35 \mathrm{~m}$ entre plantas e 1,50 m entre fileiras, com o objetivo de produção de frutos.
\end{abstract}

Palavras-chave: Campomanesia adamantium, população de plantas, resíduo orgânico

\begin{abstract}
Spacing between plants and addition of chicken manure in the biomass production of plants and in the chemical composition of fruits of Campomanesia adamantium (Cambess.) O. Berg. The aim of this study was to evaluate the effect of five spacing between plants and the use or not of semi-decomposed chicken manure incorporated into the soil on the biomass production of plants and on the levels of phenols, flavonoids and antioxidant activity of the extract of $C$. adamantium fruits. The experiment was carried out in the Medicinal Plant Garden - HPM, of Federal University of Grande Dourados/UFGD, in Dourados-Mato Grosso do Sul State, Brazil. C. adamantium was studied under five spacing between plants in a row $(0.30$; $0.35 ; 0.40 ; 0.45$ and $0.50 \mathrm{~m}$ ) and with and without semi-decomposed chicken manure incorporated in the soil, at a dose of $10 \mathrm{t} \mathrm{ha}^{-1}$. Treatments were arranged as $5 \times 2$ factorial, in randomized block design, with four replicates. At 390 days after transplanting, the plants had $54.89 \mathrm{~cm}$ height, $10.01 \mathrm{~mm}$ stem diameter and 178.27 leaves per plant. The longitudinal $(17.34 \mathrm{~mm})$ and transverse $(18.07 \mathrm{~mm})$ diameters of the fruits did not vary with the spacing or with the use of chicken manure. The largest number (28.56 fruits plant $\left.{ }^{-1}\right)$ and greatest fresh weight $\left(83.65 \mathrm{~g} \mathrm{plant}^{-1}\right)$ of fruits were obtained for plants cultivated under spacing of 0.32 and $0.35 \mathrm{~m}$ between plants, respectively, independent of the use of chicken manure. The chicken manure induced a significant increase in phenol content and reduced flavonoid content and the antioxidant activity of the fruit pulp. The chicken manure did not influence the productivity of $C$. adamantium or the chemical composition of fruits. The use of spacing of $0.35 \mathrm{~m}$ between plants and $1.50 \mathrm{~m}$ between rows is recommended, with the aim of producing fruits.
\end{abstract}

Key words: Campomanesia adamantium, plant population, organic waste

Recebido para publicação em 10/05/2011

Aceito para publicação em 17/04/2012

Rev. Bras. Pl. Med., Botucatu, v.14, n.4, p.680-685, 2012. 


\section{INTRODUÇÃO}

A Campomanesia adamantium (Cambess.) O. Berg (Myrtaceae) é arbusto frutífero nativo do Cerrado, de ampla ocorrência, encontrado no CentroOeste e Sudeste e, em alguns casos, chegando a ultrapassar os limites do Brasil para alcançar as terras do Uruguai, Argentina e Paraguai (Lorenzi, 2008).

As folhas e os frutos apresentam substâncias que são utilizadas como anti-inflamatória, antidiarreica e anti-séptica das vias urinárias (Piva, 2002). Pavan et al. (2009) relatam que o extrato acetato de etila dos frutos de C. adamantium contribuem para atividade contra o Mycobacterium tuberculosis. Vinagre et al. (2010) sugerem que o tratamento com o decocto das folhas de $C$. xanthocarpa $\left(20 \mathrm{~g} \mathrm{~L}^{-1}\right)$ possa ser útil para a terapêutica do diabetes mellitus. Além das propriedades medicinais, os frutos da $C$. adamantium possuem sabor singular sendo apreciados pela população, por isso, são intensamente colhidos, sem a preocupação de manutenção das plantas.

O interesse na avaliação dos frutos de Campomanesia é devido à presença de compostos fenólicos, que nos últimos anos têm recebido muita atenção, por serem considerados potentes agentes antioxidantes que protegem o organismo da ação danosa dos radicais livres, responsáveis pelo envelhecimento e por doenças degenerativas como câncer, cataratas, artrite e diabetes entre outras (Giada \& Mancini Filho, 2006).

Coutinho et al. (2008) sugerem que as folhas de $C$. adamantium podem ser usadas como fonte de recursos naturais antioxidantes. Das folhas de diferentes exemplares foram observado conteúdo fenólico de 7,24 a 21,19 $\mathrm{mg} \mathrm{g}^{-1}$. Os extratos hexânico, clorofórmico e etanólico obtiveram alta atividade antioxidante, com variação de DPPH de 52,0 a 92,2\% e inibição da oxidação do ácido linoléico de 14,6 a 94,2\%.

Por ser espécie encontrada somente em áreas nativas, são escassas as informações agronômicas sobre o cultivo da $C$. adamantium. Para o cultivo de espécies medicinais é recomendado a adição de resíduos orgânicos, por serem vários os benefícios. Para as plantas, atua como fonte de nutrientes e, no solo, tem ação tamponante, aumenta a capacidade de troca catiônica-CTC, melhora a estrutura, reduz a plasticidade e a coesão, aumenta a capacidade de retenção de água e a aeração, permitindo maior penetração e distribuição das raízes (Kiehl, 2008). Segundo Lorenzi (2008), plantas do gênero Campomanesia produzem mais em solos do tipo Podzólico Vermelho-Amarelo em clima tropical quente, com baixo índice pluviométrico. Pereira et al. (2010) recomendam a utilização de substrato formado por $60 \%$ terra $+40 \%$ cama-de-frango para a produção de mudas de Tamarindus indica, pois resultou em maior altura de plantas, diâmetro de caule e produção de biomassa. Casagrande Júnior et al. (1996) observaram que a adição de vermicomposto, nas proporções de 1:1 e 3:1 v/v de solo, no substrato favoreceu o crescimento de mudas de Psidium cattleyanum.

Além do estudo da adubação orgânica, o espaçamento entre plantas pode possibilitar a distribuição mais uniforme das plantas na área, favorecendo melhor utilização da luz, água e nutrientes, incrementando a produtividade vegetal. Dentre os relatos do estudo dos espaçamentos na produção de plantas medicinais, cita-se Ramos et. al (2004), que descrevem maior produção de massa e número de capítulos florais de Chamomilla recutita no espaçamento 0,11 m entre plantas com a adição de cama-de-frango incorporada ao solo, na dose de $38 \mathrm{t} \mathrm{ha}^{-1}$. Munarin et al. (2010) observaram que a cobertura do solo com cama-de-frango não influenciou a produtividade de Arctium lappa e recomendam para o cultivo o espaçamento de $0,40 \mathrm{~m}$ entre plantas para produção de folhas e raízes.

A exploração de plantas nativas do Cerrado tem levado à redução drástica das populações naturais dessas espécies, seja pelo processo predatório de exploração, ou pelo desconhecimento dos mecanismos de perpetuação. Desta forma, o estudo do espaçamento entre plantas e uso da adubação orgânica geram conhecimentos de tecnologias para a utilização econômica das espécies nativas. É necessário gerar mais informações sobre o cultivo da C. adamantium, beneficiando populações locais, que poderão utilizar das técnicas adquiridas para produção e cultivo da espécie, reduzindo assim o risco de extinção.

O objetivo deste trabalho foi estudar o efeito de cinco espaçamentos entre plantas e o uso ou não de cama-de-frango semidecomposta incorporada ao solo, na produção de frutos e nos teores de fenóis, flavonóides e atividade antioxidante do extrato dos frutos da Campomanesia adamantium.

\section{MATERIAL E MÉTODO}

O experimento foi desenvolvimento no Horto de Plantas Medicinais (HPM), da Universidade Federal da Grande Dourados/UFGD, em Dourados-MS, no período de dezembro de 2006 a fevereiro de 2009 . O horto está situado em latitude $22^{\circ} 11^{\prime} 43.7^{\prime \prime} S$ e longitude 05456'08.5'W. O clima, segundo a classificação de Köppen é do tipo Cwa (mesotérmico úmido). As precipitações totais e temperaturas máximas e mínimas quinzenais, no período de cultivo em campo, estão apresentadas na Figura 1.

O solo, originalmente sob vegetação de Cerrado, é de topografia plana e classificado como Latossolo Vermelho Distroférrico, de textura muito argilosa, com as características químicas 4,9 de $\mathrm{pH}$ 


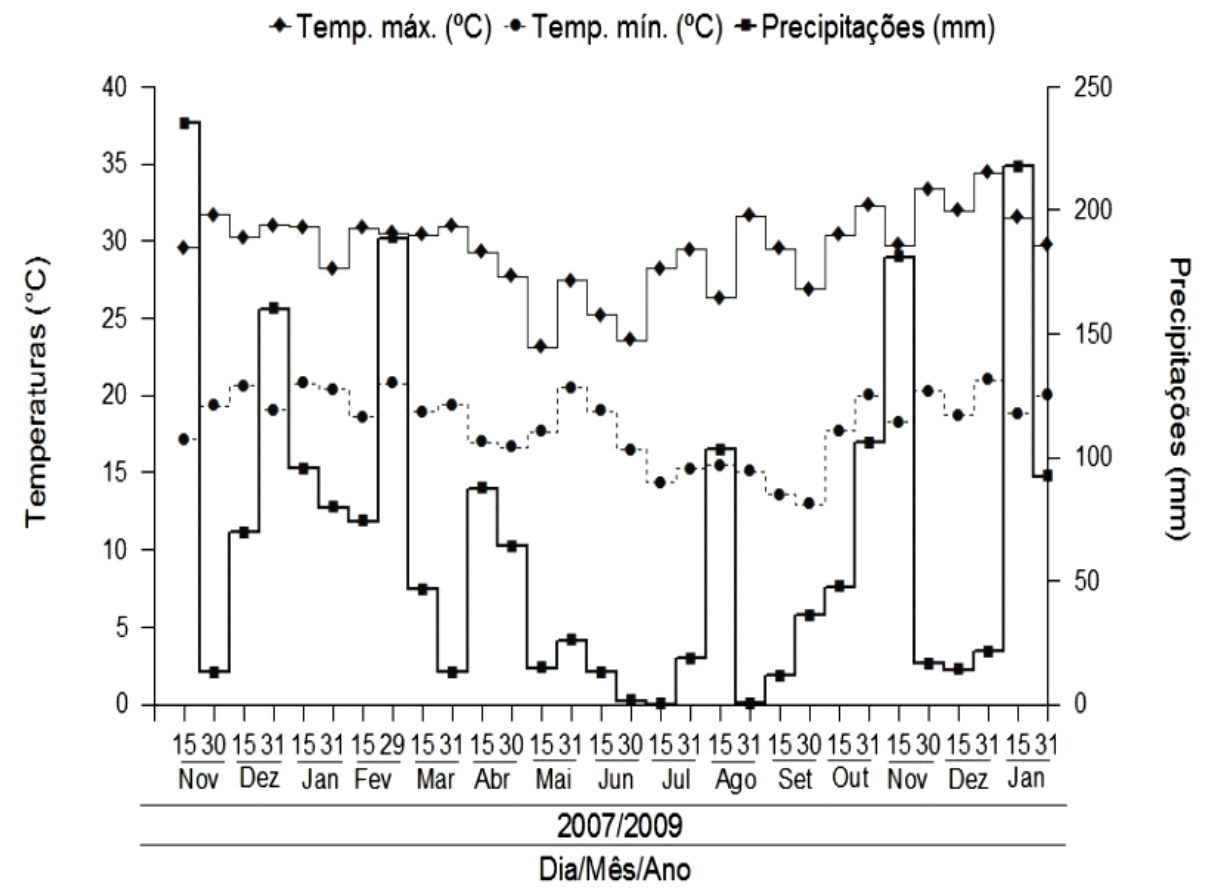

FIGURA 1. Precipitações e temperaturas máximas e mínimas, durante o ciclo de cultivo no campo da C. adamantium. UFGD, Dourados - 2007/2009.

em CaCl $; 32 \mathrm{~g} \mathrm{dm}^{-3}$ de M.O; $38 \mathrm{mg} \mathrm{dm}^{-3}$ de P; 8,$2 ; 51,3$ e $17,0 \mathrm{mmol}_{(\mathrm{c})} \mathrm{dm}^{-3} \mathrm{de} \mathrm{K}$, Ca e Mg, respectivamente.

Foi cultivada a C. adamantium (Cambess.) O. Berg sob cinco espaçamentos entre plantas na linha $(0,30 ; 0,35 ; 0,40 ; 0,45$ e $0,50 \mathrm{~m})$, em solo sem e com cama-de-frango semidecomposta incorporada, na dose de 10 t ha-1 ${ }^{-1}$ com as características químicas $2,01 \% \mathrm{~N} ; 0,89 \% \mathrm{P} ; 0,58 \% \mathrm{~K} ; 6,56 \% \mathrm{Ca} ; 0,57 \% \mathrm{Mg}$ e relação $\mathrm{C} / \mathrm{N} 9 / 1$. Os tratamentos foram arranjados como fatorial $5 \times 2$, no delineamento experimental de blocos casualizados, com quatro repetições. As parcelas tiveram área total de $3,15 \mathrm{~m}^{2}(1,5 \mathrm{~m}$ de largura $\times 2,10 \mathrm{~m}$ de comprimento) e área útil de 2,10 $m^{2}$ (1,0 m de largura e 2,10 m de comprimento), contendo uma fileira de plantas no centro do canteiro.

As sementes de $C$. adamantium foram coletadas de população de plantas nativas em área de preservação permanente da Fazenda Santa Madalena,

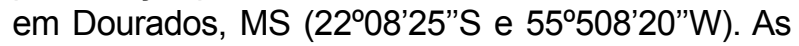
plantas foram identificadas e depositadas no Herbário DDMS, sob número 2192. A propagação foi realizada por semeadura indireta, em dezembro de 2006. As mudas foram produzidas inicialmente em bandejas de poliestireno de 128 células, preenchidas com substrato Bioplant ${ }^{\circledR}$ para hortaliças. As mudas foram mantidas em ambiente protegido com sombrite ${ }^{\circledR} 50 \%$ e irrigações diárias até atingirem cerca de $5 \mathrm{~cm}$ de altura, quando foram repicadas para sacos de polietileno de $0,15 \mathrm{x}$ $0,30 \mathrm{~m}$ preenchidos com substrato constituído de mistura de terra, areia e cama-de-frango (5:1:1). Quando as plântulas atingiram cerca de $10 \mathrm{~cm}$ de altura, foram transplantadas ao local definitivo, em novembro de 2007.
O terreno foi preparado com trator, uma semana antes do transplante, com aração e gradagem e, posteriormente, foram levantados os canteiros com rotoencanteirador incorporando imediatamente a cama-de-frango que havia sido distribuída a lanço nas parcelas correspondentes. Durante a condução do experimento foram feitas irrigações utilizando-se o sistema de aspersão com o intuito de manter o solo sempre úmido, sem exata determinação quantitativa, e considerando o regime pluviométrico. $O$ controle de plantas infestantes foi feito de forma manual dentro dos canteiros e com o auxílio de enxada entre os canteiros.

A partir dos 30 até 390 dias após o transplante (DAT) foram determinadas, mensalmente a altura de plantas, o diâmetro da base do caule a $2 \mathrm{~cm}$ do nível do solo, o número de folhas e o número de ramificações primárias e secundárias de todas as plantas contidas nas parcelas. Desde os 317 até 397 DAT, a cada dois dias, foram feitas colheitas manuais dos frutos maduros em todas as plantas contidas nas parcelas usando como índice de colheita a mudança da cor verde brilhante para verde opaco a verde amarelada. Em cada colheita, os frutos foram contados e pesados em balança digital com precisão de $0,01 \mathrm{~g}$ e medidos os diâmetros longitudinais e transversais com paquímetro digital. Após a última colheita determinou-se o número e a massa total de frutos por planta em cada tratamento.

Para realização dos testes de fenóis, flavonóides e atividade antioxidante foram preparados extratos a partir de $5 \mathrm{~g}$ da polpa dos frutos maduros 
de cada tratamento no campo, em $10 \mathrm{~mL}$ de água destilada. Os extratos foram obtidos por maceração, filtrando-se a amostra em algodão e, posteriormente, em papel-filtro. Para o teste de fenóis foram utilizados $0,1 \mathrm{~mL}$ da amostra e adicionados $1,5 \mathrm{~mL}$ de solução aquosa de carbonato de sódio $20 \% ; 0,5 \mathrm{~mL}$ de reagente Folin-Ciocalteau (1:10 v/v) e $1 \mathrm{~mL}$ de água destilada. $A$ solução foi deixada para reagir por 30 minutos antes da leitura em espectrofotômetro, em comprimento de onda de $760 \mathrm{~nm}$. O mesmo procedimento foi realizado para o teste em branco, sendo substituídos $0,1 \mathrm{~mL}$ de amostra por 0,1 mL de água destilada (Djeridane et al., 2006). Para calcular a concentração de fenóis foi preparada uma curva analítica $(1,0 ; 5,0 ; 10,0 ; 15,0$; 30,0; 40,0 $\mu \mathrm{g}$ ) empregando-se como padrão o ácido gálico. O resultado foi expresso em mg de ácido gálico por $g$ de extrato. Todos os testes foram realizados em triplicata.

Para os testes de flavonóides foram utilizados $0,5 \mathrm{~mL}$ da amostra e adicionados $1,5 \mathrm{~mL}$ de etanol $95 \% ; 0,1 \mathrm{~mL}$ de cloreto de alumínio tri hidratado10\%; 0,1 $\mathrm{mL}$ de acetato do sódio tri hidratado (1 mol L-1) e 2,8 mL de água destilada. A solução foi deixada para reagir à temperatura ambiente, por 40 minutos. Posteriormente, a leitura foi feita em espectrofotômetro (Femto 700S) no comprimento de onda de $415 \mathrm{~nm}$. O mesmo procedimento foi realizado para o teste em branco sendo substituídos $0,5 \mathrm{~mL}$ de amostra por 0,5 mL de água destilada (Lin \& Tang, 2006). Para o cálculo da concentração de flavonóides foi preparada uma curva analítica $(2,5 ; 5,0 ; 10,0 ; 20,0$; 25,$0 ; 50,0 ; 100,0$ e 125,0 $\mu \mathrm{g}$ ) empregando-se a quercetina como padrão. $O$ resultado foi expresso em mg de quercetina por g de extrato. Todos os testes foram realizados em triplicata.

O teste antioxidante com o radical livre DPPH foi realizado empregando-se solução preparada de DPPH a $0,004 \%$ em metanol. A cada amostra $(1 \mathrm{~mL})$ foram adicionados $2 \mathrm{~mL}$ da solução de DPPH, sendo a leitura feita em espectrofotômetro (Femto 700S) no comprimento de onda de $517 \mathrm{~nm}$, após o intervalo de 30 minutos de reação. Foi tomado como referência de máxima absorção, $2 \mathrm{~mL}$ da solução de DPPH adicionados a 1 $\mathrm{mL}$ de água destilada. Através das absorbâncias resultantes foi calculado o percentual de inibição. $A$ equação empregada para expressar o percentual de inibição foi \%PI $=\left[\left(A_{0}-A_{1}\right) \div A_{0}\right] \times 100 \%$, onde $A_{o}$ é a solução controle (branco) do DPPH em metanol decorridos 30 minutos de reação, $A_{1}$ corresponde à absorbância da amostra em DPPH decorridos 30 minutos de reação, empregando-se a quercetina como padrão (Kumaran \& Karunakaran, 2006).

As médias dos dados obtidos foram submetidas à análise de variância e, quando se verificou significância pelo teste $F$, foram ajustadas equações de regressão a $p>0,05$ de probabilidade (Ribeiro Júnior, 2001).

\section{RESULTADO E DISCUSSÃO}

A altura de plantas, o diâmetro da base do caule, o número de ramos primários, o número de ramos secundários, e o número de folhas, não foram influenciados significativamente pela cama-de-frango nem pelos espaçamentos entre plantas, demonstrando que prevaleceu o efeito do componente genético característico da espécie. Por outro lado, houve efeito significativo das épocas de avaliação (Figuras 2A a D). As plantas apresentaram crescimento lento no período de 120 a 270 DAT, fato que pode estar associado às condições climáticas tais como temperaturas baixas e menor pluviosidade (Figura 1), que são os fatores climáticos que mais influenciam a fenologia das plantas resultando em diferentes formas de crescimento (Alvarado et al., 2002).

Aos 390 DAT, a altura média máxima foi de $54,89 \mathrm{~cm}$, o diâmetro da base do caule mediu 10,01 $\mathrm{mm}$, e o número médio máximo de folhas foi de 178,27 folhas planta-1 (Figura 2). 0 número de ramos primários manteve-se em torno de 1,0 ramo/planta durante todo o ciclo (Figura 2D). O número de ramos secundários foi máximo aos 390 DAT, com 3,45 ramos secundários planta-1 (Figura 2D). O número de ramos secundários correspondeu à característica de arbusto da C. adamantium, tal como citado por Lorenzi (2008).

O uso ou não da cama-de-frango não influenciou significativamente os diâmetros longitudinal $(17,34 \mathrm{~mm})$ e transversal $(18,38 \mathrm{~mm})$ dos frutos, o número de frutos $(21,21$ frutos planta-1), e a massa fresca dos frutos da $C$. adamantium $\left(65,63\right.$ g planta $\left.^{-1}\right)$. Tal resultado pode estar relacionado à adequada fonte de nutrientes do solo local, que favoreceu o crescimento das plantas, tamanho, número e peso dos frutos. A cama-de-frango pode ter atuado na manutenção da umidade no solo e no desenvolvimento do sistema radicular das plantas.

O número e a massa fresca dos frutos diminuíram com o aumento dos espaçamentos entre plantas (Figura 3), sendo o maior número de frutos $(28,56$ frutos planta-1) obtido sob espaçamento estimado de $0,32 \mathrm{~m}$ e a maior massa fresca de frutos $\left(83,65\right.$ g planta-1 $\left.^{-1}\right)$ sob espaçamento de 0,35 m entre plantas (Figuras $3 \mathrm{~A}$ e B). O menor espaçamento utilizado possivelmente não ocasionou competição entre plantas a ponto de reduzir a produção de frutos. Em áreas nativas, verifica-se que a $C$. adamantium encontra-se em grupos de plantas muito próximas, formando moitas que, muitas vezes, impossibilitam o isolamento de uma única planta.

Lal et al. (1996), estudando o efeito do espaçamento e a intensidade de poda na floração e frutificação em goiabeiras, constataram que as árvores cultivadas no espaçamento $2 \times 2 \mathrm{~m}$ tinham menor produção de frutos por árvore do que aquelas cultivadas no espaçamento $8 \times 8 \mathrm{~m}$, mas a produção por hectare

Rev. Bras. PI. Med., Botucatu, v.14, n.4, p.680-685, 2012. 

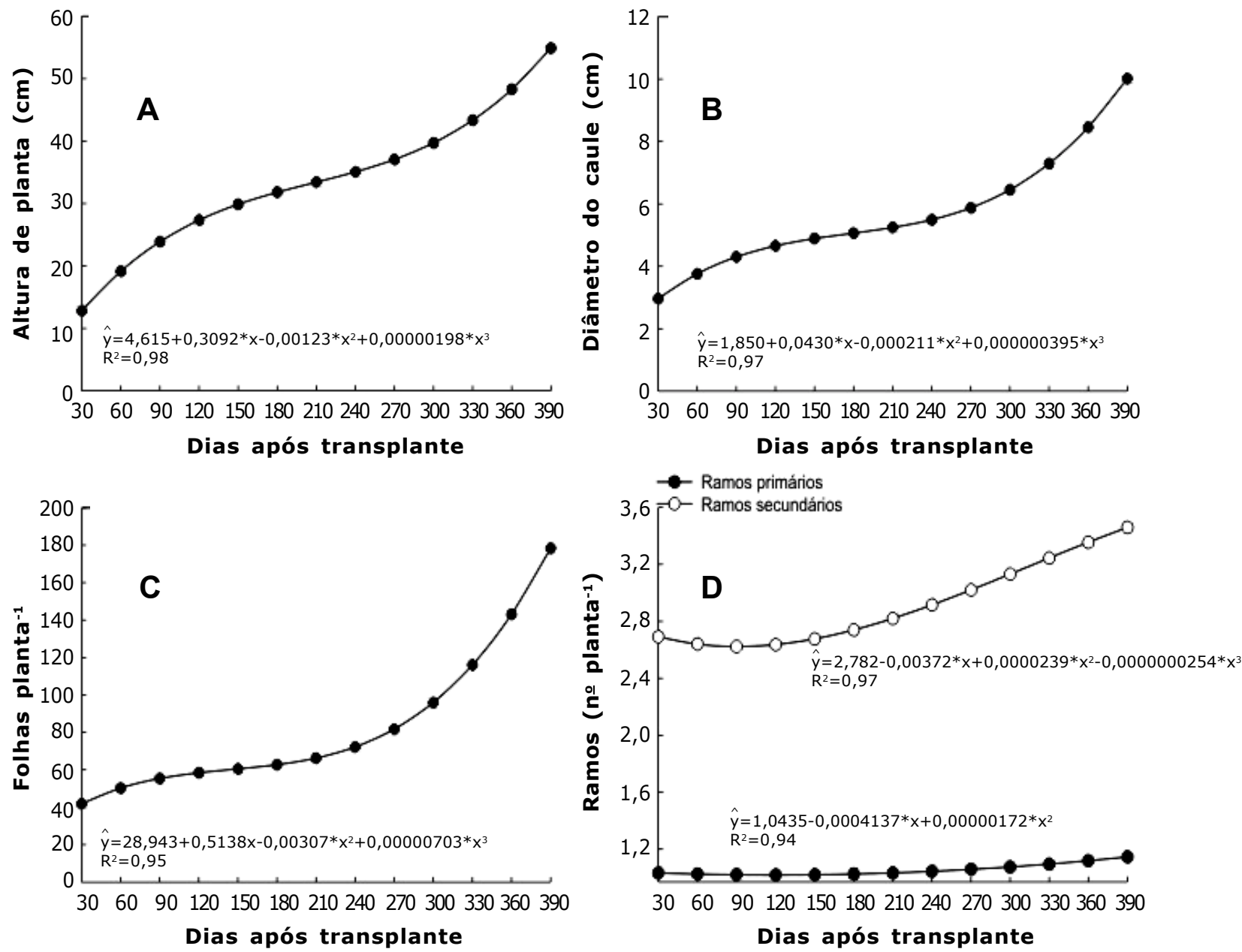

FIGURA 2. Altura de plantas (A), diâmetro do caule (B), número de folhas (C) e de ramos (D) da C. adamantium cultivada sob cinco espaçamentos entre plantas, sem e com cama-de-frango incorporada ao solo, em função de dias após transplante. UFGD, Dourados - 2009. * significativo a $5 \%$.
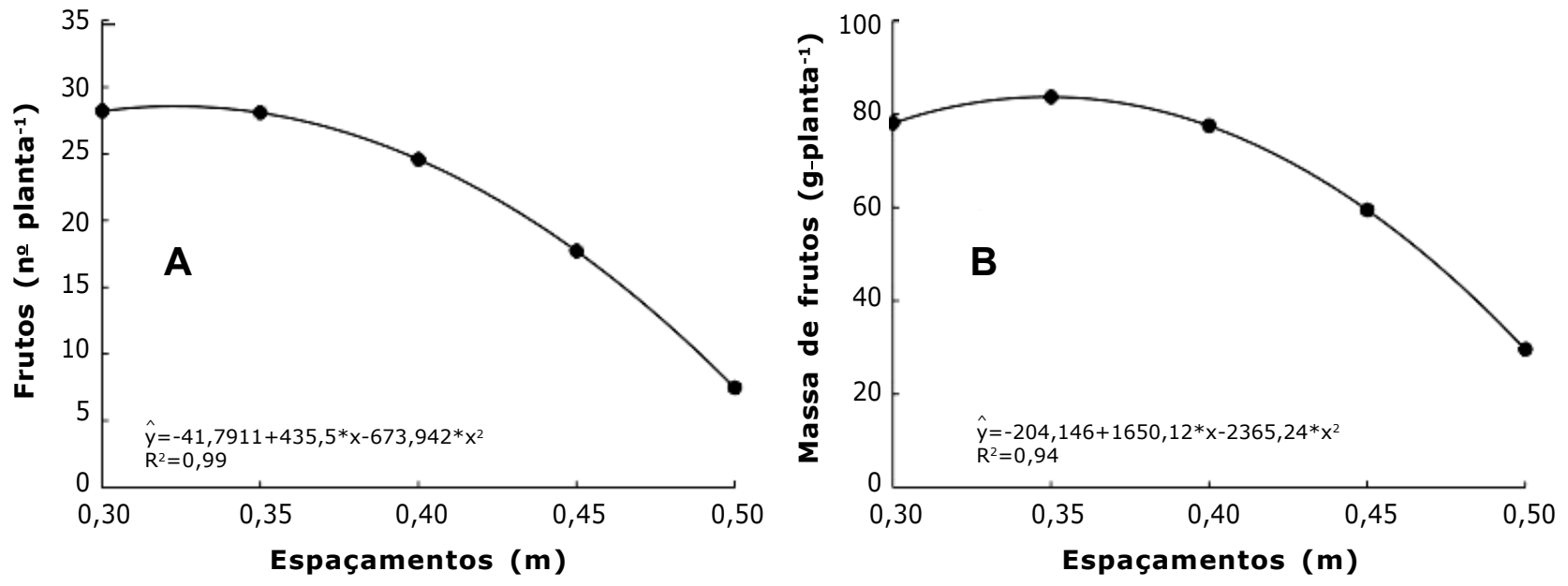

FIGURA 3. Número (A) e massa fresca (B) de frutos da $C$. adamantium cultivada sob cinco espaçamentos entre plantas. UFGD, Dourados - 2009. Os dados da cama-de-frango foram agrupados. * ${ }^{*}$ significativo a $5 \%$. 
foi dez vezes maior no menor espaçamento devido à maior população de plantas. Mandal et al. (2007), estudando o efeito da irrigação por gotejamento e espaçamento entre plantas na produtividade, qualidade, e retorno econômico de goiabeira cultivada em solo salino, também observaram que as maiores produções por hectare foram obtidas no menor espaçamento, correspondendo a 12,0 e 21,60 tha-1 após o terceiro e quarto anos de plantio, respectivamente.

Houve interação significativa para os teores de fenóis, flavonóides e atividade antioxidante da polpa dos frutos da $C$. adamantium entre cama-defrango e espaçamentos entre plantas (Figura 3); no entanto, os dados não se ajustaram a nenhum modelo de regressão. Os teores de fenóis foram 6,06\% maiores com cama-de-frango (398,26 $\left.\mathrm{mg} \mathrm{g}^{-1}\right)$ do que sem cama-de-frango (374,09 $\left.\mathrm{mg} \mathrm{g}^{-1}\right)$. Por outro lado, o teor de flavonóides foi 16,13\% maior sem cama-defrango $\left(65,93 \mathrm{mg} \mathrm{g}^{-1}\right)$ do que com cama-de-frango $(55,29$ $\mathrm{mg} \mathrm{g}^{-1}$ ) e a atividade antioxidante foi $7,18 \%$ maior sem cama-de-frango $(75,83 \%)$ do que com cama-de-frango $(70,38 \%)$. Não há relatos na literatura que expliquem a influência da adubação com cama-de-frango na produção dos teores de fenóis, flavonóides e atividade antioxidante, em nenhuma espécie medicinal. De forma geral, o extrato da polpa do fruto da $C$. adamantium pode ser utilizado como fonte de fenóis, flavonóides e atividade antioxidante. Coutinho et al. (2008) relatam para as folhas de C. adamantium, teores de compostos fenólicos de 7,24 a 21,19 $\mathrm{mg} \mathrm{g}^{-}$ ${ }^{1}$, e alta atividade antioxidante do efeito radical livre (DPPH) de 52,0 a 92,2\%, demonstrando que, além das folhas, os frutos da $C$. adamantium possuem elevados teores de fenóis, flavonóides e atividade antioxidante.

Nas condições em que foi conduzido o experimento concluiu-se que a quantidade de $10 \mathrm{t}$ ha $^{-1}$ de cama-de-frango no solo utilizado não promoveu incrementos no crescimento das plantas nem na produção e composição química dos frutos da $C$. adamantium. Recomenda-se o uso do espaçamento $0,35 \mathrm{~m}$ entre plantas e 1,50 m entre fileiras, para obtenção de maior produção de frutos da $C$. adamantium. Mais pesquisas devem ser realizadas para melhor entendimento do uso da cama-de-frango como adubo orgânico no cultivo da C. adamantium, especialmente em solos deficientes em nutrientes.

\section{AGRADECIMENTO}

À FUNDECT-MS e ao CNPq, pelas bolsas concedidas e apoio financeiro.

\section{REFERÊNCIA}

ALVARADO, M.A. et al. El cambio climático y la fenología de las plantas. Ciência UANL. v.5, p.493-500, 2002.

CASAGRANDE JÚNIOR, J.G. et al. Efeito de materiais orgânicos no crescimento de mudas de araçazeiro (Psidium cattleyanum Sabine). Revista Brasileira de Agrociência, v.2, n.3, p.187-91, 1996.

COUTINHO, I.D. et al. Determination of phenolic compounds and evaluation of antioxidant capacity of Campomanesia adamantium leaves. Eclética Química, v.33, n.4, p.53-60, 2008.

DJERIDANE, A. et al. Antioxidant activity of some algerian medicinal plants extracts containing phenolic compounds. Food Chemistry, v.97, p.654-60, 2006.

GIADA, M.L.R.; MANCINI FILHO, J. Importância dos compostos fenólicos da dieta na promoção da saúde humana. Publicatio UEPG: Ciências Biológicas e da Saúde, v.4, n.12, p.7-15. 2006.

KIEHL, E.J. Adubação orgânica - 500 perguntas e respostas. 2.ed. Piracicaba: Degaspari, 2008. 227p.

KUMARAN, A.; KARUNAKARAN, R.J. Antioxidant and free radical scavenging activity of an aqueous extract of Coleus aromaticus. Food Chemistry, v.97, p.109-14, 2006.

LAL, S.; TIWARI, J.P.; MISRA, K.K. Effect of plant spacing and pruning intensity on flowering and fruiting of guava. Annals of Agricultural Research, v.17, n.1, p.83-9, 1996. LIN, J.Y.; TANG, C.Y. Determination of total phenolic and flavonoid contents in selected fruits and vegetables, as well as their stimulatory effects on mouse splenocyte ploriferation. Food Chemistry, v.101, p.140-7, 2006.

LORENZI, H. Árvores brasileiras - manual de identificação e cultivo de plantas arbóreas nativas do Brasil. v.1, 5.ed. Nova Odessa: Instituto Plantarum, 2008. 384p.

MANDAL, L.G. et al. Effect of drip irrigation and plant spacing on yield, quality and economic return of guava (Psidium guajava L.) grown in saline soil. Acta Horticulturae, v.735, p.427-32, 2007.

MUNARIN, E.E.O. et al. Espaçamentos entre plantas e cobertura do solo com cama-de-frango na produção da bardana (Arctium lappa L.). Revista Brasileira de Plantas Medicinais, v.12, n.2, p.141-8, 2010.

PAVAN, F.R. et al. Evaluation of anti-Mycobacterium tuberculosis activity of Campomanesia adamantium (Myrtaceae). Química Nova, v.32, p.1222-6, 2009.

PEREIRA, P.C. et al. Mudas de tamarindeiro produzidas em diferentes níveis de matéria orgânica adicionada ao substrato. Revista Verde, v.5, n.3, p.152-9, 2010.

PIVA, M.G. O caminho das plantas medicinais: estudo etnobotânico. Rio de Janeiro: Mondiran, 2002. 320p.

RAMOS, M.B.M. et al. Produção de capítulos florais em função de populações de plantas e da incorporação ao solo de cama-de-aviário. Horticultura Brasileira, v.22, n.3, p.566-72, 2004.

RIBEIRO JÚNIOR, J.I. Análises estatísticas no SAEG. Viçosa: UFV, 2001. 301p.

VINAGRE, A.S. et al. Anti-diabetic effects of Campomanesia xanthcarpa Berg leaf decoction. Brazilian Journal of Pharmaceutical Sciences, v.46, p.169-77, 2010.

Rev. Bras. PI. Med., Botucatu, v.14, n.4, p.680-685, 2012. 